\title{
Application of Health Belief Model on Factors Influencing Long-Term Contraceptive Use
}

\author{
Ayu Dhiah Pitaloka'), Pawito's), Hanung Prasetya3) \\ 1)Masters Program in Public Health, Universitas Sebelas Maret \\ ${ }^{2)}$ Faculty of Social and Political Sciences, Universitas Sebelas Maret \\ 3)School of Health Polytechnic Surakarta
}

\begin{abstract}
Background: Family planning is one of the strategies to reduce maternal mortality. Data in 2017 shows that in Indonesia, out of 37,338,265 couples of reproductive age there were $18.63 \%$ who did not do family planning. Women of reproductive age (WRA) who have not done family planning can affect reproductive health. This study aimed to analyze factors influencing long-term contraceptive method (LTCM) using health belief model theory.

Subjects and Method: This was a cross sectional study conducted in Sleman, Central Java, from March to April 2019. A sample of 220 women of reproductive age was selected by quota sampling. The dependent variable was LTCM use. The independent variables were perceived severity, perceived susceptibility, perceived benefit, cues to action, self-efficacy, education, and culture. The data was collected by questionnaire and analyzed by a multiple logistic regression.

Results: Perceived severity $(\mathrm{OR}=8.02 ; 95 \% \mathrm{CI}=2.62$ to $24.51 ; \mathrm{p}<0.001)$, perceived susceptibility $(\mathrm{OR}=12.16 ; 95 \% \mathrm{CI}=3.65$ to $40.42 ; \mathrm{p}<0.001)$, perceived benefit $(\mathrm{OR}=6.05 ; 95 \% \mathrm{CI}=2.10$ to 17.40 ; $\mathrm{p}=0.001)$, cues to action $(\mathrm{OR}=6.98 ; 95 \% \mathrm{CI}=2.30$ to $21.18 ; \mathrm{p}=0.001)$, self-efficacy $(\mathrm{OR}=3.60$; $95 \% \mathrm{CI}=1.23$ to $10.52 ; \mathrm{p}=0.019)$, education $(\mathrm{OR}=2.50 ; 95 \% \mathrm{CI}=1.40$ to $10.41 ; \mathrm{p}=0.029)$, culture $(\mathrm{OR}=6.65 ; 95 \% \mathrm{CI}=2.14$ to $20.62 ; \mathrm{p}=0.001)$ increased long-term contraceptive use.

Conclusions: Perceived severity, perceived susceptibility, perceived benefit, cues to action, self-efficacy, education, culture increase long-term contraceptive use.
\end{abstract}

Keywords: family planning, long-term contraceptive, health belief model

\section{Correspondence:}

Ayu Dhiah Pitaloka. Masters Program in Public Health, Universitas Sebelas Maret. Jl. Ir. Sutami 36A, Surakarta 57126, Central Java. Email: ayudhiahp@gmail.com. Mobile: +62812266896291

\section{BACKGROUND}

The population as a determinant of development in terms of the health sector must be based on population dynamics. Development efforts in the health sector are reflected in health programs through promotive preventive, curative, and rehabilitative efforts (Ministry of Health 2018).

The Center for Health Data and Information of R.I 2016 states that reproductive health is not only physical health but also overall health, namely physically, mentally, and socially and free from diseases or disabilities related to the system, function and process of reproduction. The scope of reproductive health includes maternal and child health, family planning, prevention and management of complications of sexually transmitted diseases (STD) including HIV/AIDS, adolescent reproductive health, treatment and prevention of abortion, infertility, advanced reproductive health, early detection of cancer reproductive tract, sexual violence, and culture related to reproduction.

One of the health problems was reproductive health in the human life cycle, namely the lack of self-awareness in planning a family for brides. It was showed that there were still many incidences of 
Journal of Health Promotion and Behavior (2019), 4(1): 55-63

https://doi.org/10.26911/thejhpb.2019.04.01.06

pregnancies that were at risk, such as pregnancy at a young age or too old age, pregnancies that were too far or too close can lead to maternal and infant death. Indonesia's health profile data in 2016 shows that the Maternal Mortality Rate (MMR) is 305 per 100,000 live births (Ministry of Health RI, 2018)

Population growth rate (PGR) in Yogyakarta continued to increase from the period of 1990-2000 which was 0.72, then experienced an increase in the period 2000-2010 by 1.04 and based on data of 2010 to 2016, which was 1.18. Central Bureau of Statistics of Yogyakarta has the largest population compared to the other 4 districts (Kulon Progo, Bantul, Yogyakarta and Gunung Kidul) (BPS RI, 2018).

Family planning was one of the strategies to reduce maternal mortality, especially for women with $4 \mathrm{~T}$ conditions, who were too young to give birth $(<20$ years old), giving birth too often, close distance of giving birth, and too old to give birth (over 35 years old). In addition, family planning also aimed to create a quality family so that a sense of security, peace and hope for a better future can arise in realizing family welfare. Based on data in 2016, it showed that in Indonesia, out of $37,338,265$ couples of reproductive age, there were still $1863 \%$ of who did not do family planning (Indonesian Ministry of Health, 2018).

WRA coverage in Yogyakarta that did not do use contraceptive was 99.790 (20. $25 \%$ ) of the total WRA, which was 492,745 . From 5 regencies in Yogyakarta, in Sleman Regency active family planning members decreased from 2015 with a percentage of $75.10 \%$ to $74.8 \%$ in 2016 . The working area of Mlati II Health Center, it was noted to have the lowest FP achievement compared to other health centers in Sleman regency which was $72.95 \%$ (Indonesian Ministry of Health, 2018).
One of the ways to improve health services was production and family planning through counseling. One method of counseling was applying. Murti (2018) states that the theory of Health Belief Model (HBM) is influenced by several factors, including perceived vulnerability, perceived severity, perceived benefits, perceived barriers, cues to act and self-efficacy (Murti, 2018)

Aulia (2016), using the health belief model study concluded that there was a relationship between perceived vulnerability, seriousness, benefits and barriers and the act of early detection of cervical cancer using the IVA method among WRA at the Padang Pasir Health Center in 2016 (Aulia, 2016).

Nugrahani et al. (2017) concluded that there was a relationship between perceived susceptibility, perceived severity, perceived threat, perceived benefit, perceived barrier, and cues to action. Riantini et al. (2018) stated that there was a significant difference before and after counseling on the knowledge of premarital couple.

\section{SUBJECTS AND METHOD \\ 1. Study Design \\ This was an analytic observational study with a cross sectional design. The study was conducted in Sleman Regency. \\ 2. Population and Sample}

The target population was women of reproductive age. Source population was women of reproductive age in Mlati, Depok III, Kalasan, Ngaglik, and Ngemplak community health centers, in Sleman, Yogyakarta, from March to April 2019. A sample of 220 women of reproductive age was selected by quota sampling.

\section{Study Variables}

The dependent variable was long-term contraceptive use. The independent variables 
were perceived severity, perceived susceptibility, perceived benefit, cues to action, self-efficacy, education, and culture.

\section{Definition Operational of Variables} Family planning. Long-term contraceptive use was family planning actions that aim to maintain reproductive health and prosper the family by using long-term contraception. The measurement scale was categorical.

Perceived severity. Perceived severity was a person's perception of the severity or seriousness of an illness.

Perceived susceptibility. Perceived susceptibility was defined as a person's perception of the risk of suffering from a particular disease or the adverse effects of an illness. The measurement scale was continuous.

Perceived benefit. Perceived benefit was a person's perception about the benefits that would be felt if someone changed the behavior. The measurement scale was continuous.

Cues to action. Cues to action was a trigger factor for actions that can come from inside or outside. The measurement scale was continuous.

Self efficacy. Self-efficacy was defined as self confidence about changes in behavior that would be carried out. The measurement scale was continuous.

Education. Education was something that was taken through government agencies. The measurement scale was continuous.

Culture. Culture was defined as all systems of ideas, actions, and works produced by humans in social life that would be used as human claims by learning in the future. The measurement scale was continuous.

\section{Data Analysis}

The data were analyzed by a multiple logistic regression to determine the relationships of independent variables and dependent variable.

\section{Research Ethics}

Research ethics included informed consent, anonymity, confidentiality, and ethical clearance. Ethical clearance was obtained from Dr. Moewardi Hospital, Surakarta, Central Java, with number: 500/ UN27.6/KEPK/2018.

\begin{tabular}{l} 
RESULTS \\
\hline 1. Sample Characteristics \\
Sample characteristics were described in \\
Table 1.
\end{tabular}
Table 1.

\section{Table 1. Sample Characteristics}

\begin{tabular}{lcc}
\hline Characteristics & n & \% \\
\hline Religion & & \\
Islam & 193 & 87.7 \\
Catholic & 9 & 4.0 \\
Christian & 17 & 7.7 \\
Hindu & 1 & 0.6 \\
\hline
\end{tabular}

Table 1 showed that the sample who were Muslim were 193 (87.7\%), Catholic were 9 (4.0\%), Christians were 17 (7.7\%), and Hindu was 1 (0.6\%).

\section{Univariate Analysis}

Table 2 showed that study subjects with high perceived severity was 171 (77.7\%), high perceived vulnerability susceptibility was 164 (74.35\%), high perceived benefit was $159(71.4 \%)$, cues to action was 153 (69.5\%), self-efficacy was 157 (71.4\%), high education was 154 (70.0\%), and culture was 158 (71.8\%).

\section{Bivariate Analysis}

Bivariate analysis to examine the effects of perceived susceptibility, perceived severity, perceived benefit, cues to action, self efficacy, education, culture, and long term contraceptive use. The results of bivariate analysis can be showed in Table 3 .

Table 3 showed that there were positive relationship of perceived susceptibility $(\mathrm{OR}=4.86 ; 95 \% \mathrm{CI} 2.50$ to $9.43 ; \mathrm{p}<0.001)$, perceived severity $(\mathrm{OR}=6.81,95 \%$ CI 3.39 to 13.66 ; $\mathrm{p}<0.001)$, perceived benefit $(\mathrm{OR}=$ 
Journal of Health Promotion and Behavior (2019), 4(1): 55-63

https://doi.org/10.26911/thejhpb.2019.04.01.06

6.21; $95 \% \mathrm{CI}=3.19$ to $12.12 ; \mathrm{p}<0.001)$, cues to action $(\mathrm{OR}=3.56 ; 95 \% \mathrm{CI} 1.88$ to 6.73 ; $\mathrm{p}<0.001)$, self efficacy $(\mathrm{OR}=3.82 ; 95 \% \mathrm{CI}$ 2.01 to $7.29 ; \mathrm{p}<0.001$ ), high education

Table 2. Univariate analysis

\begin{tabular}{lcc}
\hline Independent Variables & n & \% \\
\hline Long-term contraceptive use & 165 & 74.5 \\
Yes & 56 & $25 \cdot 5$ \\
No & 171 & 77.7 \\
Perceived severity & 49 & 22.3 \\
High & & \\
Low & 164 & 74.5 \\
Perceived susceptibility & 56 & $25 \cdot 5$ \\
High & & 72.3 \\
Low & 159 & 27.7 \\
Percepived benefit & 61 & 69.5 \\
High & & 30.5 \\
Low & 153 & 71.4 \\
Cues to Action & 67 & 28.6 \\
Ligh & & \\
Self-Efficacy & 157 & 70.0 \\
High & 63 & 30.0 \\
Low & & 71.8 \\
Education & 154 & 28.2 \\
\hline high school & 66 & \\
Cuigh school & & \\
High & 158 & 62 \\
Low & & \\
\hline
\end{tabular}

\section{Multivariate Analysis}

Table 4 showed the results of multivariate analysis. Table 4 showed that women of reproductive age with high perceived susceptibility increased long-term contraceptive use 8.02 times than those with low perceived susceptibility $(\mathrm{OR}=8.02 ; 95 \% \mathrm{CI}=2.62$ to 24.52; $\mathrm{p}<0.001)$.

Women of reproductive age with high perceived severity increased long-term contraceptive use 12.16 times than those with low perceived severity $(\mathrm{OR}=12.16$ 95\%CI 3.65 to $40.42 ; \mathrm{p}<0.001$ ).

Women of reproductive age with high perceived benefit increased long-term contraceptive use 6.05 times than those with low perceived benefit $(\mathrm{OR}=6.05 ; 95 \% \mathrm{CI}=2.10$ to 17.40; $\mathrm{p}=0.001$ ).
$(\mathrm{OR}=6.87 ; 95 \% \mathrm{CI}=3.53$ to $13.36 ; \mathrm{p}$ $<0.001)$, and culture (OR= 5.32; 95\% CI 2.76 to 10.25 ; $\mathrm{p}<0.001)$ on long-term contraceptive use.
Women of reproductive age with high cues to action increased long-term contraceptive use 6.98 times than those with low cues to action $(\mathrm{OR}=6.98 ; 95 \% \mathrm{CI} 2.30$ to 21.18; $\mathrm{p}=0.001$ ).

Women of reproductive age with strong self-efficacy increased long-term contraceptive use 3.60 times than those with low self efficacy $(\mathrm{OR}=3.6095 \% \mathrm{CI}=1.23$ to $10.52 ; \mathrm{p}=$ 0.019).

Women of reproductive age with high education increased long-term contraceptive use 2.50 times than those with low education $(\mathrm{OR}=2.5095 \% \mathrm{CI}=1.40$ to $10.41 ; \mathrm{p}=0.029)$.

Women of reproductive age with supportive culture increased long-term contraceptive use 6.65 times than those without supportive culture $(\mathrm{OR}=6.65 ; 95 \% \mathrm{CI}=2.14$ to $2.72 ; \mathrm{p}<0.001)$. 
$\underline{\text { Table 3. Bivariate analysis }}$

\begin{tabular}{|c|c|c|c|c|c|c|c|c|}
\hline \multirow{3}{*}{ Independent Variables } & \multicolumn{4}{|c|}{ LTCM use } & \multirow[t]{3}{*}{ OR } & \multicolumn{2}{|l|}{ CI 95\% } & \multirow[t]{3}{*}{$\mathbf{p}$} \\
\hline & \multicolumn{2}{|c|}{ Yes } & \multicolumn{2}{|c|}{ No } & & \multirow{2}{*}{$\begin{array}{c}\text { Lower } \\
\text { Limit }\end{array}$} & \multirow{2}{*}{$\begin{array}{l}\text { Upper } \\
\text { Limit }\end{array}$} & \\
\hline & $\mathbf{n}$ & $\%$ & $\mathbf{n}$ & $\%$ & & & & \\
\hline \multicolumn{9}{|l|}{ Perceived Vulnerability } \\
\hline High & 136 & 82.9 & 28 & 17.1 & 4.86 & 2.50 & 9.43 & $<0.001$ \\
\hline Low & 28 & 50 & 28 & 50 & & & & \\
\hline \multicolumn{9}{|l|}{ Perceived Severity } \\
\hline High & 143 & 83.6 & 28 & 16.4 & 6.81 & 3.39 & 13.66 & $<0.001$ \\
\hline Low & 21 & 42.9 & 28 & 57.1 & & & & \\
\hline \multicolumn{9}{|l|}{ Perceived Benefit } \\
\hline High & 135 & 84.9 & 24 & 151 & 6.21 & 3.19 & 12.12 & $<0.001$ \\
\hline Low & 29 & 47.5 & 32 & 52.5 & & & & \\
\hline \multicolumn{9}{|l|}{ Cues to Action } \\
\hline High & 126 & 82.4 & 27 & 17.6 & 3.56 & 1.88 & 6.73 & $<0.001$ \\
\hline Low & 38 & 56.7 & 29 & 43.3 & & & & \\
\hline \multicolumn{9}{|l|}{ Self-Efficacy } \\
\hline High & 130 & 82.3 & 28 & 17.7 & 3.82 & 2.01 & 7.29 & $<0.001$ \\
\hline Low & 34 & 54.8 & 28 & 45.2 & & & & \\
\hline \multicolumn{9}{|l|}{ Education } \\
\hline$>$ high school & 132 & 86.3 & 21 & $13 \cdot 7$ & 6.87 & 3.53 & $13 \cdot 36$ & $<0.001$ \\
\hline$\leq$ high school & 32 & 47.8 & 35 & 52.5 & & & & \\
\hline \multicolumn{9}{|l|}{ Culture } \\
\hline High & 133 & 84.2 & 25 & 15.8 & $5 \cdot 32$ & 2.76 & 10.25 & $<0.001$ \\
\hline Low & 31 & 50 & 31 & 50 & & & & \\
\hline
\end{tabular}

Table 4. The Results of Multivariate Analysis

\begin{tabular}{lcccc}
\hline \multirow{2}{*}{ Independent Variables } & \multirow{2}{*}{ OR } & \multicolumn{2}{c}{ CI 95\% } & \multirow{2}{*}{ p } \\
\cline { 3 - 4 } & & Lower Limit & Upper Limit & \\
\hline Perceived severity (high) & 8.02 & 2.62 & 24.52 & $<0.001$ \\
Perceived susceptibility (high) & 12.16 & 3.65 & 40.42 & $<0.001$ \\
Perceived benefit (high) & 6.05 & 2.10 & 17.40 & 0.001 \\
Cues to act (yes) & 6.98 & 2.30 & 21.18 & 0.001 \\
Self efficacy (strong) & 3.60 & 1.23 & 10.52 & 0.019 \\
Education (>HS) & 2.50 & 1.40 & 10.41 & 0.029 \\
Culture (supportive) & 6.65 & 2.14 & 2.72 & 0.001 \\
$\mathrm{~N}=220$ & & & & \\
LR chi ${ }^{2}=126.45$ & & & & \\
$\mathrm{p}<0.001$ & & & & \\
$\mathrm{R}^{2}=50.66 \%$ & & & & \\
Log likelihood= & & & & \\
\hline
\end{tabular}

\section{DISCUSSION}

1. The relationship of perceived severity and long-term contraceptive use

The level of severity has a statistically significant relationship with long-term contraceptive methods. This esd in line with the study of Davies et al. (2016), which states that someone who has a perception of long-term contraceptive methods is susceptible to experience side effects and has a greater likelihood of taking preventive measures so that no side effects occur. Conversely, someone who has a low per- 
Journal of Health Promotion and Behavior (2019), 4(1): 55-63

https://doi.org/10.26911/thejhpb.2019.04.01.06

ceived susceptibility to experience the side effects of a smaller possibility to take the necessary actions to prevent the occurrence of these side effects. An unwanted pregnancy was one of the severities experienced by women of reproductive age who were also not using long-term contraception.

Brown (2010), stated that perceived severity increased long-term contraceptive use among women of reproductive age and it can prevent unwanted pregnancies.

\section{The relationship of perceived sus- ceptibility and long-term contra- ceptive use}

The results of the analysis showed that there was a relationship between perceived susceptibility and long-term contraceptive use. Someone who has a perception that a long-term contraceptive method was life threatening, caused disability, pain, broad impact would not use long-term contraceptive methods (Davies et al. 2016). Women of reproductive age were prone to repeated unwanted pregnancies. Morse et al. (2012) mentions that unwanted repetitive pregnancies can be prevented by long-term contraceptive use, so women of reproductive age who were prone to unwanted pregnancies can use long-term contraception.

\section{The relationship of perceived bene- \\ fit and long-term contraceptive use}

The results of the analysis showed that there was a relationship between perceived benefit and long-term contraceptive use.

The results of this study were in line with Chipeta et al. (2010) which stated that long-term contraceptive methods were influenced by the benefits. Someone who knew the benefits of long term contraceptive methods would choose to use family planning compared to those who did not know. Turok et al. (2016), mentions that one of the benefits felt by women of reproductive age in long-term contraceptive use is very effective contraception and if it was taking off, the fertility would return quickly and without special care. Women with low sexual experience and a history of low sexual activity would need to use long-term contraception. One of the benefits of long term contraception was possessing high effectiveness in preventing pregnancy, especially unwanted pregnancy (Hoopes et al. 2016)

\section{The relationship of cues to action and long-term contraceptive use}

The results of the analysis showed that there was a relationship between cues to action and long-term contraceptive use.

Davies et al. (2016) stated that long term contraceptive use was influenced by cues to action. Cues to action were stimuli needed to trigger the decision making process so that health behavior changes occur. Cues to act were incidents, people, or things that can move people to change their behavior. Provision of health personnel who received training in the installation of long-term contraception can increase long term contraceptive use in women of reproductive age (Luchowski et al. 2014). Family encouragement, especially husband, can be a factor in increasing long-term contraceptive use in women of reproductive age (Yalew et al. 2015).

\section{The relationship of self-efficacy} and long-term contraceptive use

The results of the analysis showed that there was a relationship between self efficacy and long-term contraceptive use.

Long-term contraceptive use was affected by self-efficacy about how certain methods can affect relationships with partners. Someone who believed that long-term contraceptive methods can be beneficial and did not think that they were able to do it, then the change would not be tried (Chipeta et al. 2010). 


\section{The relationship of education and long-term contraceptive use}

The results of the analysis showed that there was a relationship between education and long-term contraceptive use.

Wijaya et al. (2019) stated that there is a significant relationship between education and long-term contraceptive use. The higher a person's education, the easier it was for someone to take the option to use long-term contraception. Education and counseling on long-term contraception can increase long-term contraceptive use in women of reproductive age (Ortiz, 2019). Teferra (2015) stated that education and employment were one of the factors which support long-term contraceptive use for women of reproductive age.

Education was a learning process that can improve knowledge and information. Women with higher education would have more knowledge about long-term contraceptive methods, both regarding benefits, side effects, advantages, disadvantages, barriers to contraceptive use (Maghfiroh et al. 2019; Haile, 2018; Yakubu and Salisu, 2018).

\section{The relationship of culture and long-term contraceptive use}

The results of the analysis showed that there was a relationship between culture and long-term contraceptive use.

The results of this study were in line with Blackstone et al. (2017) who stated that culture strongly influences a person's behavior to use long-term contraceptive methods. Cultural factors were equally important in a couple's decision about contraception.

When a new family moved, they would be faced with the challenge of adjusting to a new society and a new way of life, they might rely heavily on traditional culture regarding family, sexuality, and fertility. While health care providers must be careful to not attribute religion, social and cultural characteristics to women who seek advice on contraception, they need to be aware that different value systems can influence decision making on contraceptive (Pinter et al., 2016).

\section{AUTHOR CONTRIBUTIONS}

Ayu Dhiah Pitaloka played a role in collecting and processing data analysis; Pawito examined the conceptual framework and methodology; Hanung Prasetya wrote the interpretation of data analysis.

\section{FUNDING AND SPONSORSHIP}

This study used personal fund.

\section{CONFLICT OF INTEREST}

The researchers did not have any conflict of interest.

\section{ACKNOWLEDGEMENT}

The authors would like to thank the community health centers for giving permission in data collection.

\section{REFERENCE}

Aulia D (2016). Health beliefs model (HBM) of cervical cancer early detection behavior with IVA method on childbearing woman in Padang Pasir. Primary Health Center 2016, 2(1); 213-221. https://doi.org/10.1186/s13104.015.09746

Blackstone SR, Nwaozuru, U, Iwelunmor J (2017). Factors influencing contraceptive use in sub-saharan Africa: a systematic review. International Quarterly of Community Health Education, 37(2):79-91. https://doi.org/10.1177/0272684X16685254.

BPS RI (2018). Statistik Indonesia 2018 (Indonesia Statistics 2018). Badan Pusat Statistik. 
Journal of Health Promotion and Behavior (2019), 4(1): 55-63

https://doi.org/10.26911/thejhpb.2019.04.01.06

Brown A (2010). Long-term contraceptives.

Best Practice and Research: Clinical Obstetrics and Gynaecology, 24 (5): 617-631. https://doi.org/10.1016/j.bpobgyn.2010.04.005

Chipeta EK, Chimwaza W, Kalilani PL (2010). Contraceptive knowledge, beliefs and attitudes in rural malawi: misinformation, misbeliefs and misperceptions. Malawi Medical Journal, 22(2): 38-41. https://doi.org/10.4314/mmj.v22i2.58790

Hoopes AJ, Ahrens KR, Gilmore K, Cady J, Haland WL, Oelschlager AMA, Prager $S$ (2016). Knowledge and acceptability of long-acting reversible contraception among adolescent women receiving schoolbased primary care services. Journal of Primary Cere and Community Health, 7(3): 165-70. https://doi.org/10.1177/2150131916641095

Kementerian Kesehatan RI (2018). Data dan informarsi profil kesehatan indonesia 2017 (Indonesian health profile data and information 2017).

Luchowski AT, Anderson BL, Power ML, Raglan GB, Espey E, Schulkin J (2014). Obstetrician gynecologists and contraception: long-acting reversible contraception practices and education. Contraception, 89(6): 573-83. https://doi.org/10.1016/j.contraception.2014.02.004

Maghfiroh A, Budihastuti UR, Nurhaeni IDA (2019). Path analysis on factors affecting the choice of female surgical contraceptive method in Kendal, Central Java. Journal of Maternal and Child Health, 4(3): 146-157. https://doi.org/10.26911/thejmch.2019.04.03.02

Morse J, Freedman L, Speidel JJ, Thompson KMJ, Stratton L, Harper CC (2012). Postabortion contraception: qualitative interviews on counseling and provision of longacting reversible contraceptive methods. Perspectives on Sexual and Reproductive Health, 44(2): 10o-6. https://doi.org/10.13$63 / 4410012$

Murti B (2018). Teori perilaku dan promosi kesehatan (1st ed.) (Behavioral theory and health promotion (1st ed.)). Surakarta: Universita Sebelas Maret.

Nugrahani RR, Budihastuti UR, Pamungkasari EP (2017). Health belief model on the factors associated with the use of HPV vaccine for the prevention of cervical cancer among women in Kediri, East Java. Journal of Epidemiology and Public Health, 2(1): 123-131. https://doi.org/10.26911/jepublichealth.2017.02.01.07

Pinter B, Hakim M, Seidman DS, Kubba A, Kishen M, Di Carlo C (2016). Religion and family planning. European Journal of Contraception and Reproductive Health Care, 21(6): 486-495. https://doi.org/10.1080/13625187.2016.1237631

Ramos-Ortiz ALD, Beth SA (2019). Using the theory of planned behavior and self-identity to explore women's decision-making and intention to switch from combined oral contraceptive pill (COC) to long-acting reversible contraceptive (LARC). BMC Women's Health, 19(82): 324-654. https://doi.org/https://doi.org/10.1186/s12905-019-0772-8

Roderique-Davies G, McKnight C, John B, Faulkner S, Lancastle D (2016). Models of health behaviour predict intention to use long-acting reversible contraception. BMC Women's Health, 12(6): 507-512. https://doi.org/10.1177/1745505716678231

Shimeka Teferra A (2015). Determinants of long-acting contraceptive use among 
reproductive age women in Ethiopia: evidence from EDHS 2011. Science Journal of Public Health, 3(1): 143-149. https://doi.org/10.11648/j.sjph.20150301 .33

Tariku Tesfaye Haile BBA (2018). The prevalence and determinants of preference of long term contraceptive methods among married women in arba minch town, Ethiopia. International Journal of Biomedical materials research, 2(6): 26-34. https://doi.org/10.11648/j.ijbmr.20180602.11

Turok DK, Gawron LM, dan Lawson S (2016). New developments in long-acting reversible contraception: the promise of intrauterine devices and implants to improve family planning services. Fertility and Sterility, 106(6): 1273-1281. https://doi.org/10.1016/j.fertnstert.2016.09.034

Wijaya VF, Rahardjo SS, dan Adriani RB (2019). Religious belief, social support, and the acceptance of intrauterine device among women of reproductive age in Klaten, Central Java. Journal of Maternal and Child Health, 4(3): 201211. https://doi.org/10.26911/thejmch.2019.04.03.07

Yakubu I, Salisu WJ (2018). Determinants of adolescent pregnancy in Sub-Saharan Africa: a systematic review. Reproductive Health, 5(1): 256-267. https://doi.org/10.1186/s12978-0180460-4

Yalew SA, Zeleke BM, Teferra AS (2015). Demand for long acting contraceptive methods and associated factors among family planning service users, Northwest Ethiopia: a health facility based cross sectional study. BMC Research Notes. https://doi.org/10.1186/s13104-015-0974-6 